\title{
Which treatment strategy for women with symptoms of urinary tract infection?
}

\author{
(@) $(1) \Theta$ OPEN ACCESS \\ Many women could avoid antibiotics
}

\author{
Lars Bjerrum professor ${ }^{1}$, Morten Lindbæk professor ${ }^{2}$
}

\begin{abstract}
${ }^{1}$ Faculty of Health and Medical Sciences, Section of General Practice, University of Copenhagen, Oester Farimagsgade 5, DK-1014, Copenhagen, Denmark; ${ }^{2}$ Antibiotic Centre for Primary Care, Department of General Practice, Institute of Health and Society, University of Oslo, PO Box 1130 Blindern, 0317 Oslo, Denmark
\end{abstract}

Uncomplicated urinary tract infection (UTI) is the most common bacterial infection in women. Most women experience at least one episode during their lives, and each year about $10 \%$ receive one or more courses of antibiotics for UTI. ${ }^{12}$ Most women with typical symptoms are treated empirically, though up to half of them do not have clinically significant bacteriuria, and evidence indicates that many women with symptoms of UTI will recover without antibiotic treatment. ${ }^{3}$

Studies that compared antibiotics with placebo in women with uncomplicated UTI report a delayed cure in the placebo group, but most become symptom free within a week. ${ }^{34}$ Prescribing antibiotics to patients with self limiting conditions contributes to antimicrobial resistance. The World Health Organization considers antimicrobial resistance to be one of the three most important public health problems globally, and initiatives to reduce inappropriate and superfluous prescribing are essential if we are to maintain effective antibiotic treatment for future generations.

In a linked paper, Gágyor and colleagues (doi:10.1136/bmj. h6544) report a pragmatic double blind trial to investigate whether initial treatment with the non-steroidal

anti-inflammatory drug (NSAID) ibuprofen can help to reduce antibiotic prescribing in women in primary care with symptoms suggestive of uncomplicated UTI. ${ }^{5}$ Nearly two thirds of women treated with ibuprofen did not receive antibiotics during the four week follow-up. They did, however, have a significantly higher burden of symptoms than women randomised to antibiotics (fosfomycin). Women given ibuprofen had their symptoms for a day longer, and about $60 \%(\mathrm{n}=143)$ still had still symptoms after four days compared with about half of those given fosfomycin initially. After one week, only $70 \%(n=163)$ of women in the NSAID group were symptom free compared with $82 \%(n=186)$ of women in the antibiotic group.
Clearly, initial treatment with a NSAID can reduce the use of antibiotics in women with uncomplicated UTI, but the trade-off is a greater burden of symptoms.

The overall rate of acute pyelonephritis was low. Five women developed this complication after initial treatment with ibuprofen compared with one in the antibiotic group. The difference was not significant, but the trial was underpowered for this uncommon outcome. Initial treatment with fosfomycin led to a higher incidence of adverse effects such as nausea and diarrhoea ( $23 \% v 17 \%$ in ibuprofen group). One woman treated with ibuprofen experienced the serious adverse effect of gastrointestinal bleeding, which was considered to be related to the drug treatment.

Overall, the study suggests that about two thirds of women with symptoms of uncomplicated UTI who were treated with ibuprofen could recover without antibiotics. The reduced consumption of antibiotics in women initially treated with NSAIDs was, however, associated with a moderately higher symptom burden. In an earlier placebo controlled Swedish study in the same group of patients, $42 \%$ in the placebo group needed an antibiotic, a proportion comparable with antibiotic prescribing in the NSAID group in the present study. ${ }^{3}$

All the women in the trial of Gágyor and colleagues gave a urine sample for culture. ${ }^{5}$ Among women with positive results, those treated initially with ibuprofen had a significantly higher burden of symptoms than women given fosfomycin, and a substantial number of women treated with ibuprofen needed antibiotics during follow-up ( 0.49 courses per patient). Among women with negative results on urine culture, however, there was no significant difference in burden of symptoms between the two treatment groups, and antibiotic use in the women initially treated with ibuprofen was low ( 0.10 courses per patient). This indicates, perhaps not surprisingly, that urine culture can help to identify the individuals most likely to benefit from antibiotics. 
Symptoms of uncomplicated UTI are uncomfortable, and most women will want to start effective treatment as soon as possible. The challenge in general practice is how to identify those who need antibiotics. Overtreatment could lead to adverse effects, and most patients are aware that overuse of antibiotics leads to antimicrobial resistance. Patients do not want antibiotics unless they are necessary. Antimicrobial treatment should therefore be initiated only if treatment is expected to reduce or shorten the symptom burden or reduce the risk of complications. ${ }^{6}$

In patients with severe and persistent symptoms, microbiological examination of urine can help the GP to identify the micro-organisms causing the infection. In Nordic countries, many GPs have direct access to point of care testing such as urine phase contrast microscopy, culture, and direct susceptibility testing to identify patients who need antibiotic treatment. ${ }^{7-9}$ In the study by Gágyor and colleagues, only a third of patients with uncomplicated UTI needed antibiotics during the four weeks of follow-up, ${ }^{5}$ so a strategy of delayed prescription for patients with light to moderate symptoms might also be a feasible strategy. We need trials of delayed prescriptions for UTI. ${ }^{10}$ Delayed prescribing has been shown to reduce antibiotic prescriptions for respiratory tract infections by $50-70 \% .^{11} 12$

Competing interests: We have read and understood the BMJ policy on declaration of interests and declare the following interests: none.

Provenance and peer review: Commissioned; not peer reviewed.

1 Colgan R, Williams M. Diagnosis and treatment of acute uncomplicated cystitis. Am Fam Physician 2011:84: 771-6. 22010614

2 Foxman B, Barlow R, D'Arcy H, Gillespie B, Sobel JD. Urinary tract infection: self-reported incidence and associated costs. Ann Epidemiol 2000;10: 509-15. doi:10.1016/S10472797(00)00072-7 11118930
3 Ferry SA, Holm SE, Stenlund H, Lundholm R, Monsen TJ. The natural course of uncomplicated lower urinary tract infection in women illustrated by a randomized placebo controlled study. Scand J Infect Dis 2004;36: 296-301. doi:10.1080/00365540410019642 15198188

4 Little P, Moore MV, Turner S. Effectiveness of five different approaches in managemen of urinary tract infection: randomised controlled trial. BMJ 2010;340: c199. doi:10.1136/ bmj.c199 20139214

5 Gágyor I, Bleidorn J, Kochen MG, Schmiemann G, Wegscheider K, Hummers-Pradier E. buprofen versus fosfomycin for uncomplicated urinary tract infection in women: randomised controlled trial. BMJ 2015;351: h6544.

6 Ferry SA, Holm SE, Stenlund H, Lundholm R, Monsen TJ. Clinical and bacteriological outcome of different doses and duration of pivmecillinam compared with placebo therapy of uncomplicated lower urinary tract infection in women: the LUTIW project. Scand J Prim Health Care 2007:25: 49-57, doi:10,1080/02813430601183074 17354160

7 Kolmos HJ, Little P. Controversies in management: should general practitioners perform diagnostic tests on patients before prescribing antibiotics?BMJ 1999;318: 799-802. doi: 10.1136/bmj.318.7186.799 10082712

8 Holm A, Cordoba G, Sørensen TM, Jessen LR, Siersma V, Bjerrum L. Point of care susceptibility testing in primary care-does it lead to a more appropriate prescription of antibiotics in patients with uncomplicated urinary tract infections? Protocol for a randomized controlled trial. BMC Fam Pract2015;16: 106. doi:10.1186/s12875-015-0322-x 26292908

9 Bjerrum L, Grinsted P, Petersen PH, Søgaard P. Standardised procedures can improve the validity of susceptibility testing of uropathogenic bacteria in general practice. Scand J Prim Health Care 2000;18: 242-6. doi:10.1080/028134300448823 11205094

10 Knottnerus BJ, Geerlings SE, Moll van Charante EP, ter Riet G. Women with symptoms of uncomplicated urinary tract infection are often willing to delay antibiotic treatment: a prospective cohort study. BMC Fam Pract 2013;14: 71. do:10.1186/1471-2290-14:71 23721260

11 Little P, Moore M, Kelly JPIPS Investigators. Delayed antibiotic prescribing strategies for respiratory tract infections in primary care: pragmatic, factorial, randomised controlled trial. BMJ 2014;348: g1606. doi:10.1136/bmj.g1606 24603565

12 Høye S, Gjelstad S, Lindbæk M. Effects on antibiotic dispensing rates of interventions to promote delayed prescribing for respiratory tract infections in primary care. Br J Gen Pract 2013;63: 777-86. doi:10.3399/bjgp13X674468 24267861

Published by the BMJ Publishing Group Limited. For permission to use (where not already granted under a licence) please go to http://group.bmj.com/group/rights-licensing/ permissions

This is an Open Access article distributed in accordance with the Creative Commons Attribution Non Commercial (CC BY-NC 3.0) license, which permits others to distribute, remix, adapt, build upon this work non-commercially, and license their derivative works on different terms, provided the original work is properly cited and the use is non-commercial. See: http://creativecommons.org/licenses/by-nc/3.0/. 